\title{
Cathodic Cage Plasma Nitriding: An Innovative Technique
}

\author{
R. R. M. de Sousa, ${ }^{1}$ F. O. de Araújo, ${ }^{2}$ J. A. P. da Costa, ${ }^{3}$ A. de S. Brandim, ${ }^{1}$ \\ R. A. de Brito, ${ }^{4}$ and C. Alves Jr. ${ }^{4}$ \\ ${ }^{1}$ Grupo de Pesquisa em Materiais e Metrologia, Departamento de Mecânica, Instituto Federal IF-PI, 64000040 Teresina, PI, Brazil \\ ${ }^{2}$ Departamento de Ciências Exatas e Naturais, Universidade Federal Rural do Semi-Árido, 59625900 Mossoró, RN, Brazil \\ ${ }^{3}$ Departamento de Física, UERN, Campus Central, 59610210 Mossoró, RN, Brazil \\ ${ }^{4}$ LabPlasma, Departamento de Física, UFRN, Campus Universitário, 59072970 Natal, RN, Brazil
}

Correspondence should be addressed to R. R. M. de Sousa, romulorms@gmail.com

Received 4 August 2011; Revised 3 November 2011; Accepted 6 December 2011

Academic Editor: Thierry Grosdidier

Copyright ( $\odot 2012$ R. R. M. de Sousa et al. This is an open access article distributed under the Creative Commons Attribution License, which permits unrestricted use, distribution, and reproduction in any medium, provided the original work is properly cited.

Cylindrical samples of AISI 1020, AISI 316, and AISI 420 steels, with different heights, were simultaneously treated by a new technique of ionic nitriding, entitled cathodic cage plasma nitriding (CCPN), in order to evaluate the efficiency of this technique to produce nitrided layers with better properties compared with those obtained using conventional ionic nitriding technique. This method is able to eliminate the edge effect in the samples, promoting a better uniformity of temperature, and consequently, a smaller variation of the thickness/height relation can be obtained. The compound layers were characterized by X-ray diffraction, optical microscopy, and microhardness test profile. The results were compared with the properties of samples obtained with the conventional nitriding, for the three steel types. It was verified that samples treated by CCPN process presented, at the same temperature, a better uniformity in the thickness and absence of the edge effect.

\section{Introduction}

Conventional plasma nitriding has been employed a lot in the industry, due to several advantages in relation to other nitriding processes (gas nitriding and salt bath nitriding), such as higher gas economy and smaller processing time, since the diffusion velocity of nitrogen $\left(\mathrm{N}_{2}\right)$ in plasma nitriding is higher [1]. This process is used to improve superficial properties like hardness, wear, and corrosion resistances, in order to increase the useful life of nitrided components. However, it presents some inconveniences like edge effect in the sample surface, hollow cathode effect, nonuniform temperature, and arcing during the treatment, especially in pieces with complex geometry $[2,3]$.

When samples with different dimensions are nitrided by conventional plasma process, they present a thermal gradient between the surface and sample holder. In samples with height of $10 \mathrm{~mm}$, the difference of temperature between the top surface and sample holder can reach $373 \mathrm{~K}$ [4].
In this work, a new plasma nitriding technique entitled cathodic cage plasma nitriding (CCPN) based on multiple hollow cathode effects is used and the results compared with the conventional plasma nitriding. This technique presents some advantages compared to the conventional method, including process efficiency and the production of layers with uniform thickness. The samples are totally involved by a metallic cage, where a high cathodic potential is applied, so the plasma is not formed directly on the sample surface, but in the cathodic cage. A ceramic disk (In this work, machined with aluminum oxide) is placed on the samples holder in order to electrically isolate the samples from the cathode. Besides, the temperature inside the nitriding chamber is uniform, and the thermal gradient is very small [5].

\section{Experimental}

Samples of AISI 1020, AISI 316, and AISI 420 steels, machined with heights of $1,3,5,8$, and $10 \mathrm{~mm}$, respectively, 
were used to carry out the tests. All the specimens were previously annealed and submitted to a metallographic preparation, where they were mounted in epoxy resin, mechanically ground (using sandpapers of 320,400, 600, and 1200) and polished (with alumina 1 and $0.3 \mu \mathrm{m}$ ). After the metallographic procedure, the samples were cleaned in an ultrasound machine with acetone, and treated by CCPN technique, in a plasma nitriding reactor. The system used in conventional nitriding is composed by a power source with maximum output voltage and DC current of $1500 \mathrm{~V}$ and $1.5 \mathrm{~A}$, respectively. In cathodic cage technique the same configuration is used, the only modification is the use of a cathodic cage. A schematic picture of the plasma reactor is shown in Figure 1. It consists of a cylindrical chamber (diameter: $30 \mathrm{~cm}$ and height: $40 \mathrm{~cm}$ ) made in stainless steel in which the negative polarized electrodes are applied and the rest of the chamber held at ground potential (anode). The cage is manufactured with 316 stainless steel (thickness: $8 \mathrm{~mm}$, diameter: $112 \mathrm{~mm}$, height: $25 \mathrm{~mm}$ and hole diameter: $8 \mathrm{~mm}$ ). The holes have a uniform distribution, and they are positioned in a distance of $9.2 \mathrm{~mm}$ between the centers of adjacent holes. The lateral minimum distance between samples and the cage is $28 \mathrm{~mm}$ [6]. Two samples to each height $(1,3,5,8$, and $10 \mathrm{~mm})$ were placed onto the insulating aluminum oxide disk which function as the sample holder, according to Figure 1. In this configuration, the plasma is formed on the cathodic cage walls and not directly on the sample surface.

The AISI 1020 steel samples were treated for $3 \mathrm{~h}$ while the samples of AISI 316 and 420 steels are treated for $5 \mathrm{~h}$, using pressures of 250 and $500 \mathrm{~Pa}$. The samples of AISI 1020, were treated under the temperatures of 673,773 , and $823 \mathrm{~K}$, the samples of AISI 316 under the temperatures of $673 \mathrm{~K}$, 723 , and $773 \mathrm{~K}$, while for the AISI 420 steel samples 623 and $673 \mathrm{~K}$. All the treatments were made with a nitriding mixture of $80 \% \mathrm{~N}_{2}+20 \% \mathrm{H}_{2}$, in a total flow of $20 \mathrm{sccm}$.

The phase composition and texture were analyzed by $\mathrm{XRD}$, using $\mathrm{Cu} \mathrm{K} \alpha$ radiation (wave length: $0.154 \mathrm{~nm}$ ), in an XRD device (Shimadzu, XRD-6000). The optical microscopy (Olympus BX60M) was used to observe the morphology and thickness of the nitrided layers. Finally, the microhardness profiles were accomplished in order to analyze the thickness and uniformity of the obtained layers, beside the elimination of the edge effect. A Vickers microhardness testing device (Pantec HVS 1000) was used to measure the hardness along the surface. A load of $100 \mathrm{gf}$ was used to carry out the indentations.

\section{Results and Discussion}

Figure 2 shows the thickness of formed layers for five samples of carbon steel AISI 1020 at the same temperature $(673,773$, and $823 \mathrm{~K}$ ) and did not present significant variation with the increase of the height for samples treated in CCPN. This fact is a consequence of the uniform temperature characteristic in this process, since in CCPN technique there are no thermal gradients between the surfaces of the sample and sample holder. The required energy to heat the samples comes from the cathodic cage, avoiding the edge effect and, consequently, promoting uniformity of the nitrided layers.

Table 1 presents the values of the thicknesses of nitrided layer for the different samples of the austenitic stainless steel AISI 316 for the two plasma nitriding techniques. A small gradient is verified in the variation of the thickness of the layers nitrided by the new technique as function of the height of the samples, especially for higher treatment temperatures $(773 \mathrm{~K})$, where the maximum variation observed in the thickness is of the order of $10 \%$, unlikely for samples treated by conventional nitriding technique the nitriding layer thickness variation was of the order of $25 \%$ between two successive sample heights value. This small nitriding layer thickness variation by cathodic cage technique, rather than being a consequence of the temperature variation inside the nitriding chamber, is only due to the different distances of the samples from the cage walls. Certainly for samples of bigger height the distance from the cage lid is smaller and consequently the nitriding species reaches the sample surface with higher energy, which is actually confirmed by the larger presence of iron nitride in the XRD diffractograms.

The XRD patterns for the AISI 316 austenitic stainless steel samples are presented in Figure 3, nitrided by CCPN, showed that the peak of "S phase" (expanded austenite) is situated in the same position for all samples with different heights, presenting the same intensity. According to Sun et al. [7], when the temperature is increased, this peak is dislocated to the left, due to the interplanar spacing increase. Therefore the absence of such peak position dislocation is indicative of the small gradient of temperature for samples with different heighs, treated in CCPN technique. The same behavior is observed to $\gamma^{\prime}-\mathrm{Fe}_{4} \mathrm{~N}$ phase.

The microhardness profiles for nitrided samples of the AISI 316 at the same temperature, but with different heights are shown in Figure 4. These values present a low variation due to the uniformity of superficial temperature, independently of the height, confirming the existence of a small thermal gradient between the top surface of the samples and the sample holder $[8,9]$.

Figure 5 presents a comparative of the samples of the AISI 316, AISI 1020, and AISI 420 steel which were nitrided by conventional method (a) and by the CCPN process (b), to show the visual aspect of the surface due the edge effect. Samples treated by conventional nitriding presented erosion rings, characteristics of the edge effect. In the case of cathodic cage plasma nitriding, the surface presents a uniform color in the whole surface area due to the elimination of the this effect for three types of steels used in this work.

Figure 6 presents the values of correspondent microhardness tests along the top surface for samples treated by conventional and CCPN nitriding process. Radial measurements were accomplished, following the regions 1,2 , and 3 in the sample surface for AISI 420, according to Figure 5. Samples treated by conventional process presented a variation in the values along the disk radius, and it was observed that region 2 presented a significant decreasing in these values. Samples treated by CCPN process presented uniform values along the disk radius, confirming the elimination of the edge effect. This fact testifies to the predominance of the mechanism of 


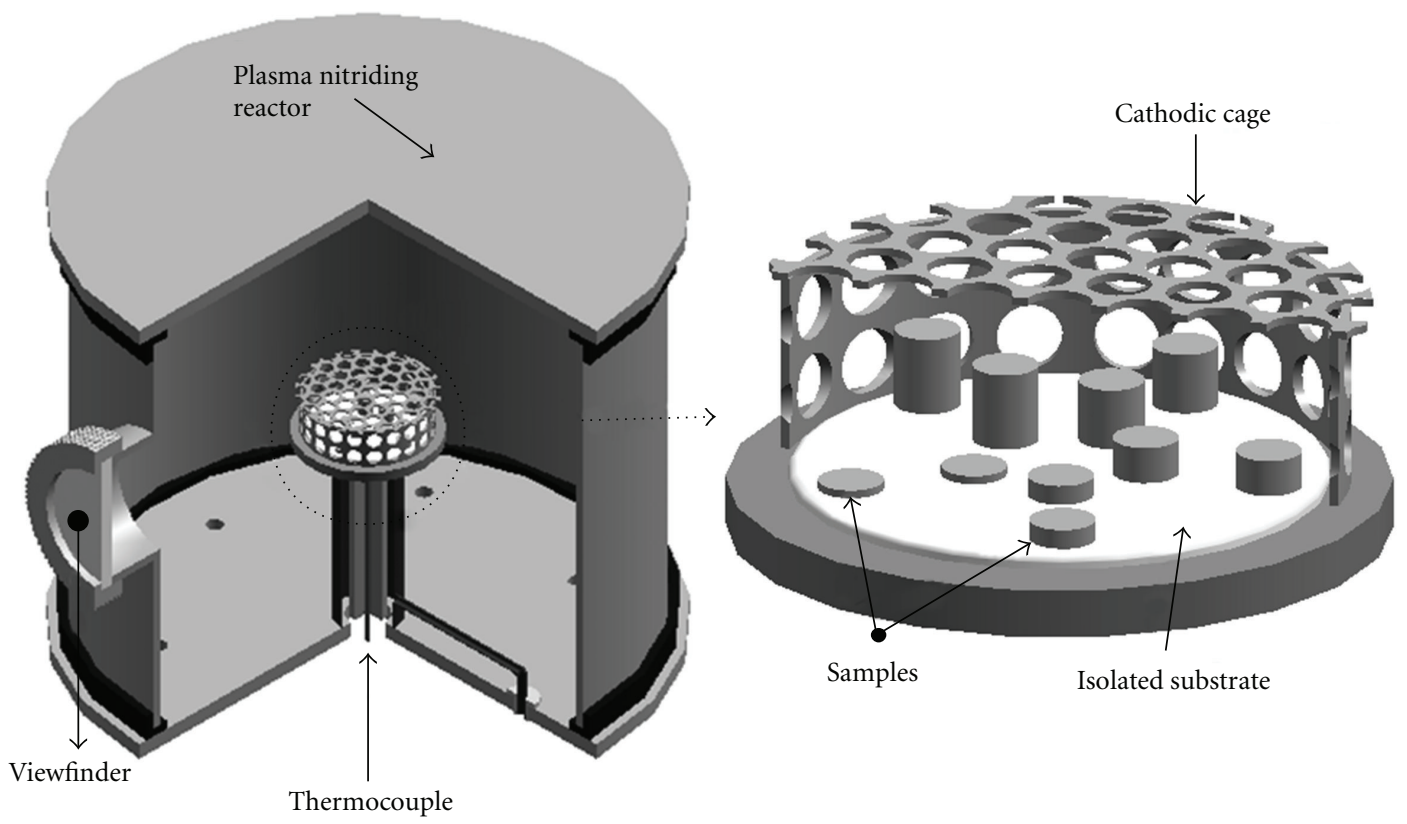

FIGURE 1: Schematic picture of the plasma reactor with the cathodic cage device, showing the disposition of samples with different heights.

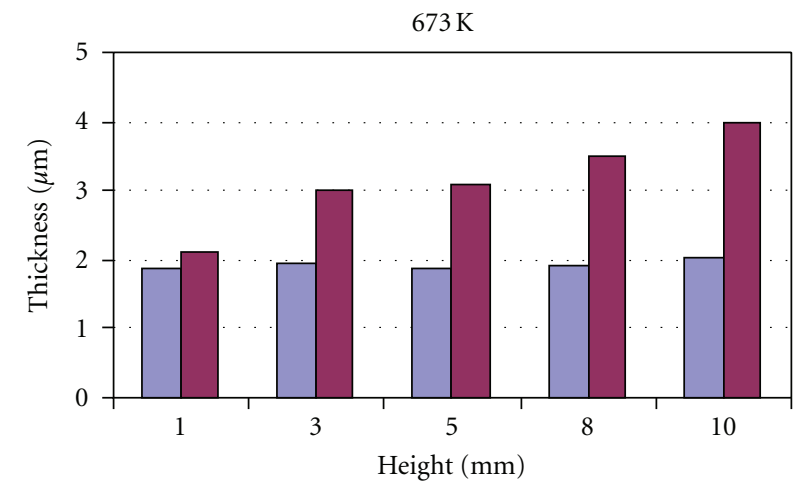

$\square$ NGC

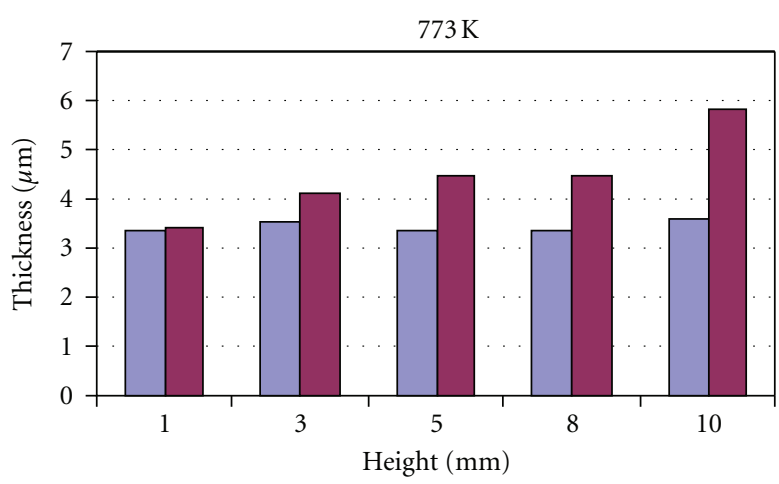

$\square$ NGC

$\square \mathrm{NI}$

(a)

(b)

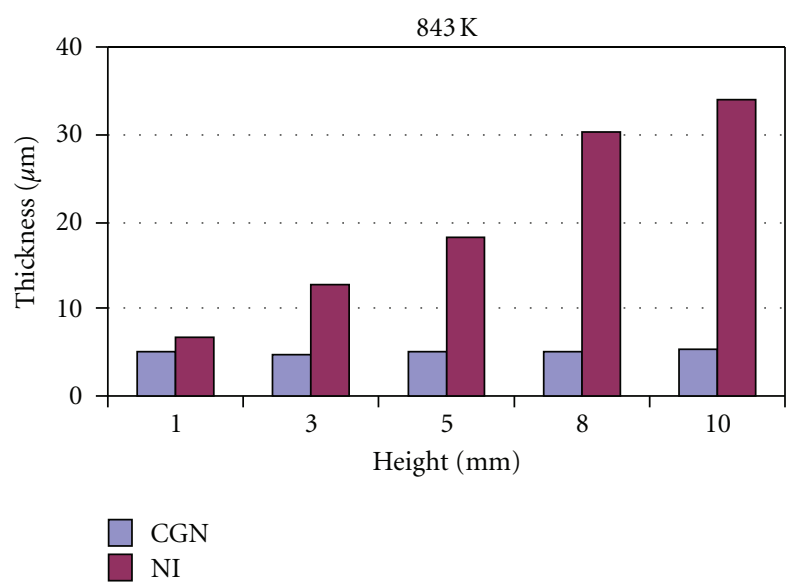

(c)

Figure 2: Thickness of layers to AISI 1020 steels samples with a height respectively 1, 3, 5, 8, and 10 mm nitrided by CCPN at (a) 673, (b) 773 , and (c) $823 \mathrm{~K}$. (3 h). 
TABLE 1: AISI 316 thickness of the nitrided layers for samples height of 1, 3, 5 and $10 \mathrm{~mm}$, at different temperatures.

\begin{tabular}{|c|c|c|c|c|c|c|c|}
\hline \multirow{3}{*}{$\begin{array}{l}\text { Sample height } \\
(\mathrm{mm})\end{array}$} & & \multicolumn{6}{|c|}{ Temperature $(\mathrm{K})$} \\
\hline & & 673 & 723 & 773 & 673 & 723 & 773 \\
\hline & & \multicolumn{3}{|c|}{ Cathodic cage } & \multicolumn{3}{|c|}{ Conventional plasma nitriding } \\
\hline 1 & \multirow{4}{*}{$\begin{array}{l}\text { Layer thickness } \\
(\mu \mathrm{m})\end{array}$} & 7,8 & 22 & 49,1 & 1,3 & 16 & 24,5 \\
\hline 3 & & 8,5 & 23 & 50,9 & 2,1 & 17,4 & 28 \\
\hline 5 & & 10 & 28 & 52,2 & 3,5 & 23,5 & 36,4 \\
\hline 10 & & 12 & 32 & 53,4 & 4,4 & 29,5 & 45,8 \\
\hline
\end{tabular}

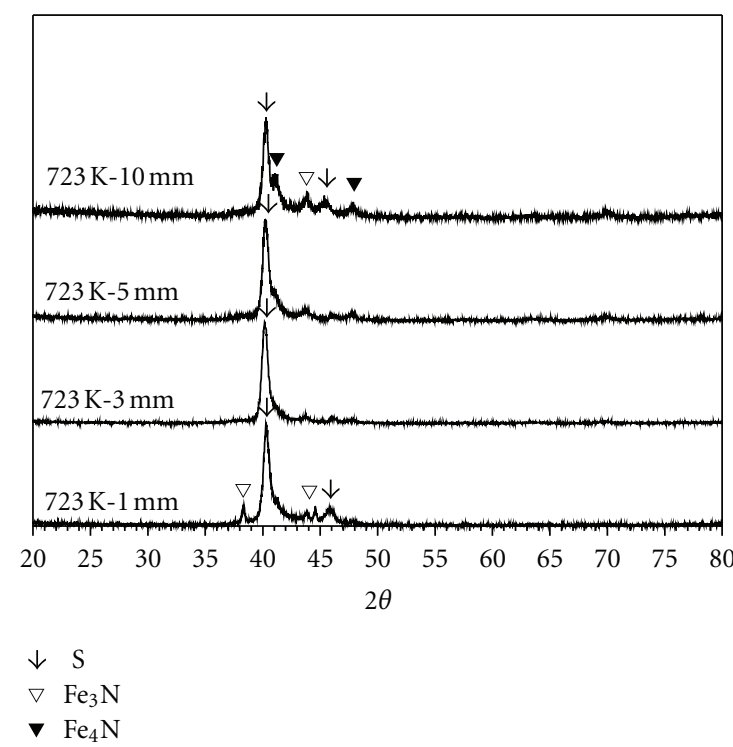

FIGURE 3: XRD patterns of AISI 316 steel samples with 1, 3, 5, and $10 \mathrm{~mm}$ and nitrided with $250 \mathrm{~Pa}, 80 \%$ of $\mathrm{N}_{2}$, at $723 \mathrm{~K},(5 \mathrm{~h})$.

sputtering of the compounds presents in the cage, followed by deposition of such compounds on the surface of samples.

\section{Conclusions}

The samples made of different materials and different heights, nitrided by CCPN, present layers with considerable uniformity of thickness. This behavior is confirmed when observing the microhardness results for the surfaces of the samples. Besides, peaks of "S phase" (expanded austenite) did not present dislocation, showing a uniform temperature for austenitic stainless steel case. The visual aspect and microhardness along the top surface are uniform for the three different steel types treated, confirming the elimination of the edge effect. In this process, undesired phenomena, like arcing and hollow cathode effect, in samples containing holes and edges, will occur in the metallic cage instead of the samples surfaces.

Except for 1020 steel, the thickness of the obtained layer is higher than the observed in conventional ionic nitriding process, since, added to the deposition effect, the samples

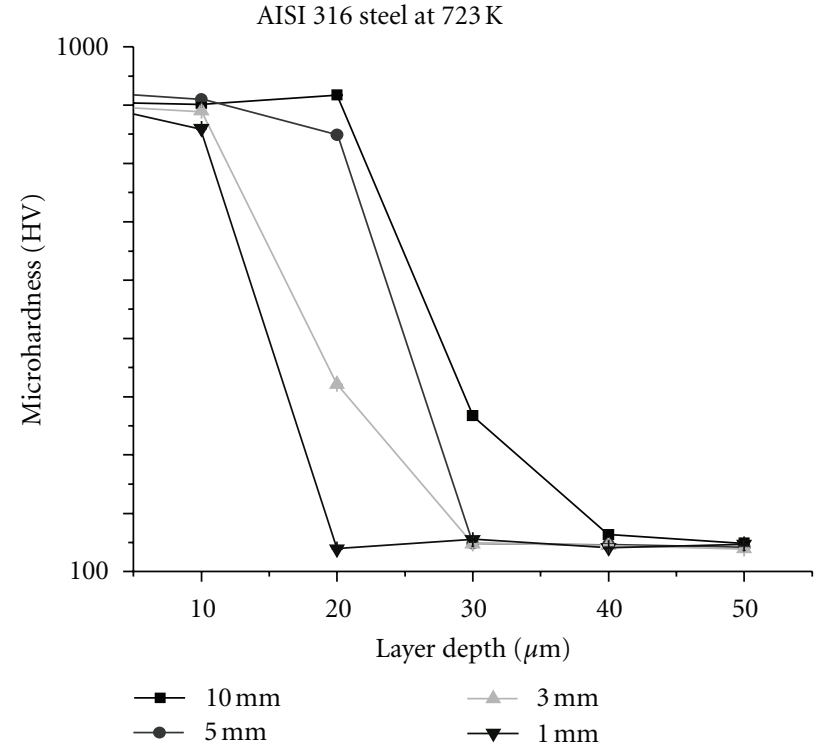

(a)

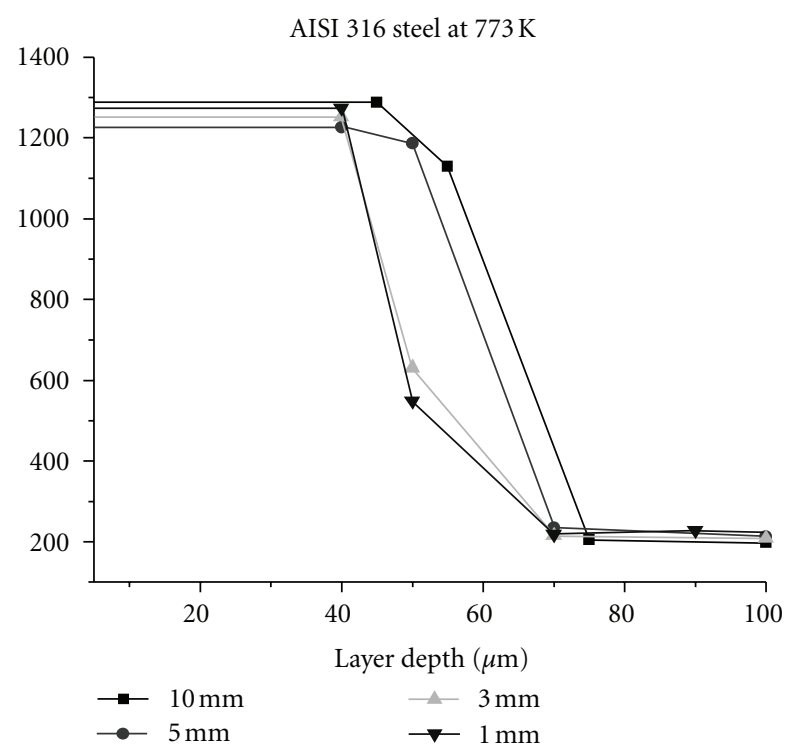

(b)

Figure 4: Profile of microhardness versus depth to the samples layer of AISI 316 stainless steel nitrided by CCN with $250 \mathrm{~Pa}$, during $5 \mathrm{~h}$ at 723 and $773 \mathrm{~K}$. 
(a)

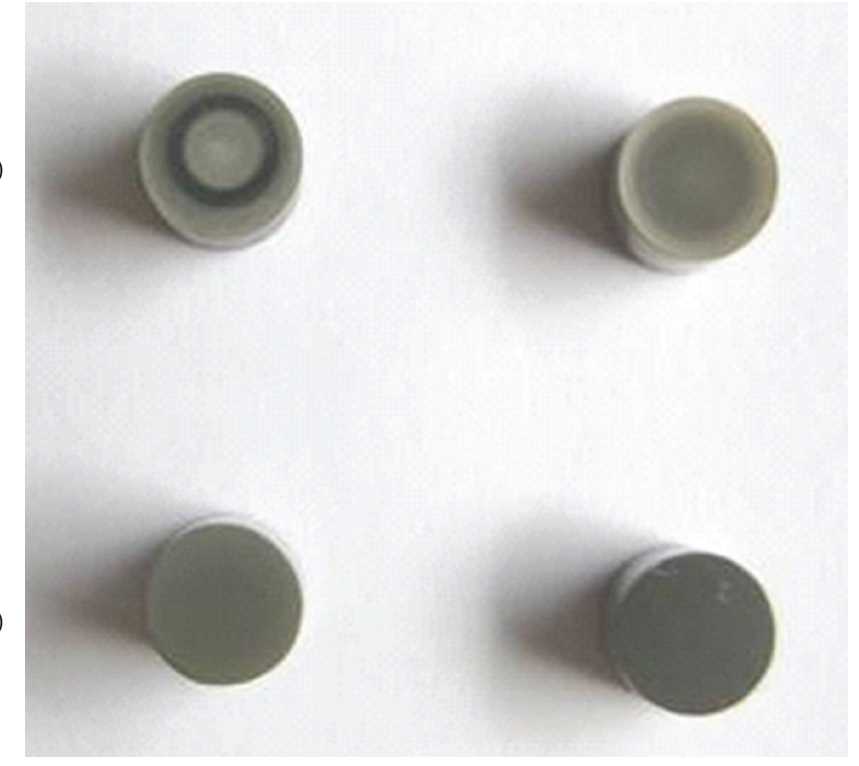

AISI 316

AISI 1020

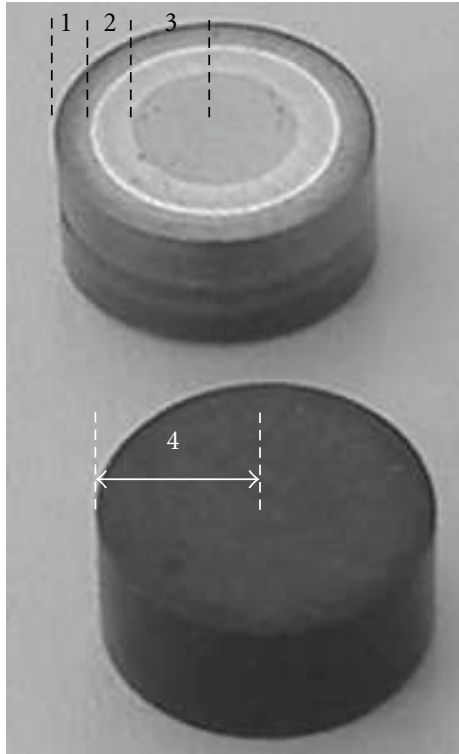

AISI 420

FIGURE 5: Micrographs of AISI 316, 1020, and 420 steel treated by (a) conventional nitriding and (b) cathodic cage plasma nitriding. The pressure used was $250 \mathrm{~Pa}$, during $5 \mathrm{~h}$ ( $3 \mathrm{~h}$ for 1020 ), at $673 \mathrm{~K}$ with $80 \% \mathrm{~N}_{2}-20 \% \mathrm{H}_{2}$ mixture.

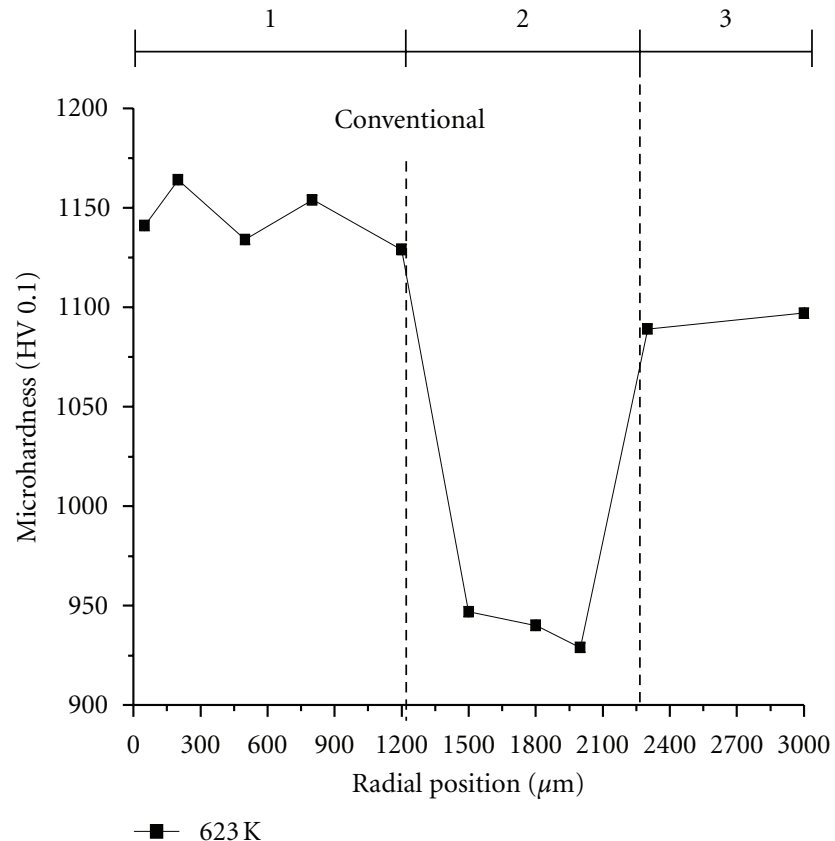

(a)

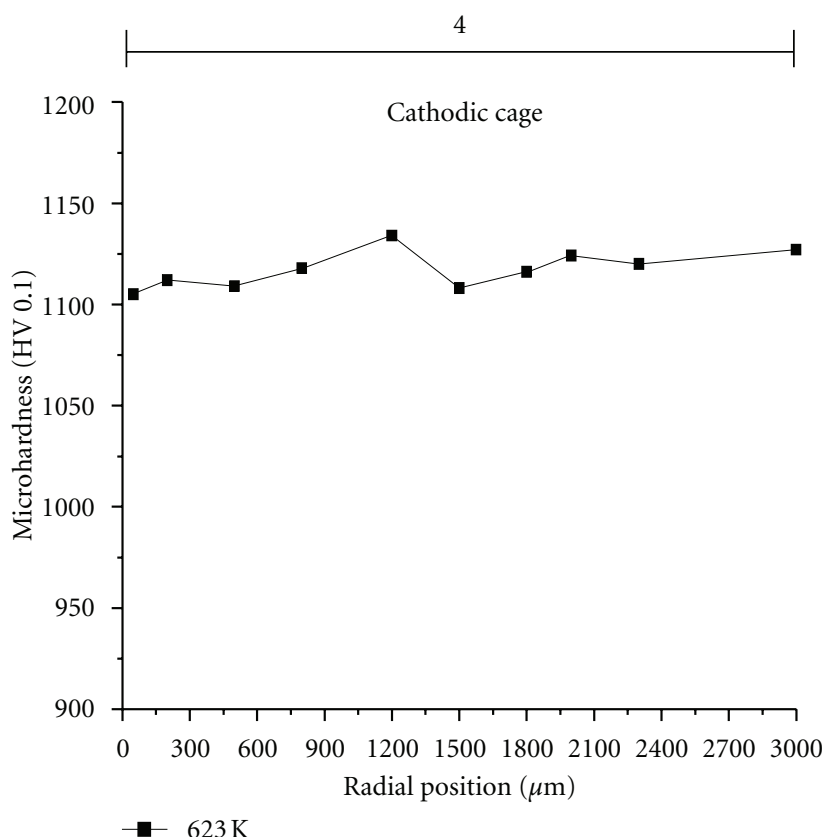

(b)

Figure 6: Microhardness along the surface of AISI 420 stee at $673 \mathrm{~K}$.

do not suffer active sputtering, which competes with the diffusion process in ionic nitriding, confirming the efficiency of the technique.

\section{Acknowledgment}

The authors are grateful to FAPEPI and CT-INFRA (MCT/CNPq) for the financial support.

\section{References}

[1] C. Alves Jr., Plasma Nitriding: Foundations and Applications, EDFRN, Natal, South Africa, 2001.

[2] C. X. Li, T. Bell, and H. Dong, "A study of active screen plasma nitriding," Surface Engineering, vol. 18, no. 3, pp. 174-181, 2002.

[3] J. Georges, "TC plasma nitriding," Heat Treatment of Metals, vol. 28, no. 2, pp. 33-37, 2001. 
[4] R. S. Sousa, Influence of the geometry of pieces and process parameters in layers nitrided by plasma, Doctor thesis, UFRN, Natal, South Africa, 2005.

[5] C. Alves Jr., F. O. de Araújo, K. J. B. Ribeiro, J. A. P. da Costa, R. R. M. Sousa, and R. S. de Sousa, "Use of cathodic cage in plasma nitriding," Surface and Coatings Technology, vol. 201, no. 6, pp. 2450-2454, 2006.

[6] C. X. Li and T. Bell, "Corrosion properties of active screen plasma nitrided 316 austenitic stainless steel," Corrosion Science, vol. 46, no. 6, pp. 1527-1547, 2004.

[7] Y. Sun, X. Y. Li, and T. Bell, "X-ray diffraction characterisation of low temperature plasma nitrided austenitic stainless steels," Journal of Materials Science, vol. 34, no. 19, pp. 4793-4802, 1999.

[8] R. R. M. de Sousa, F. O. de Araújo, K. J. B. Ribeiro, M. W. D. Mendes, J. A. P. da Costa, and C. Alves Jr., "Cathodic cage nitriding of samples with different dimensions," Materials Science and Engineering A, vol. 465, no. 1-2, pp. 223-227, 2007.

[9] R. R. M. de Sousa, F. O. de Araújo, K. J. B. Ribeiro, J. A. P. da Costa, R. S. de Sousa, and C. Alves Jr., "Uniformity of temperature in cathodic cage technique in nitriding of austenitic stainless steel AISI 316," Surface Engineering, vol. 24, no. 4, pp. 313-318, 2008. 

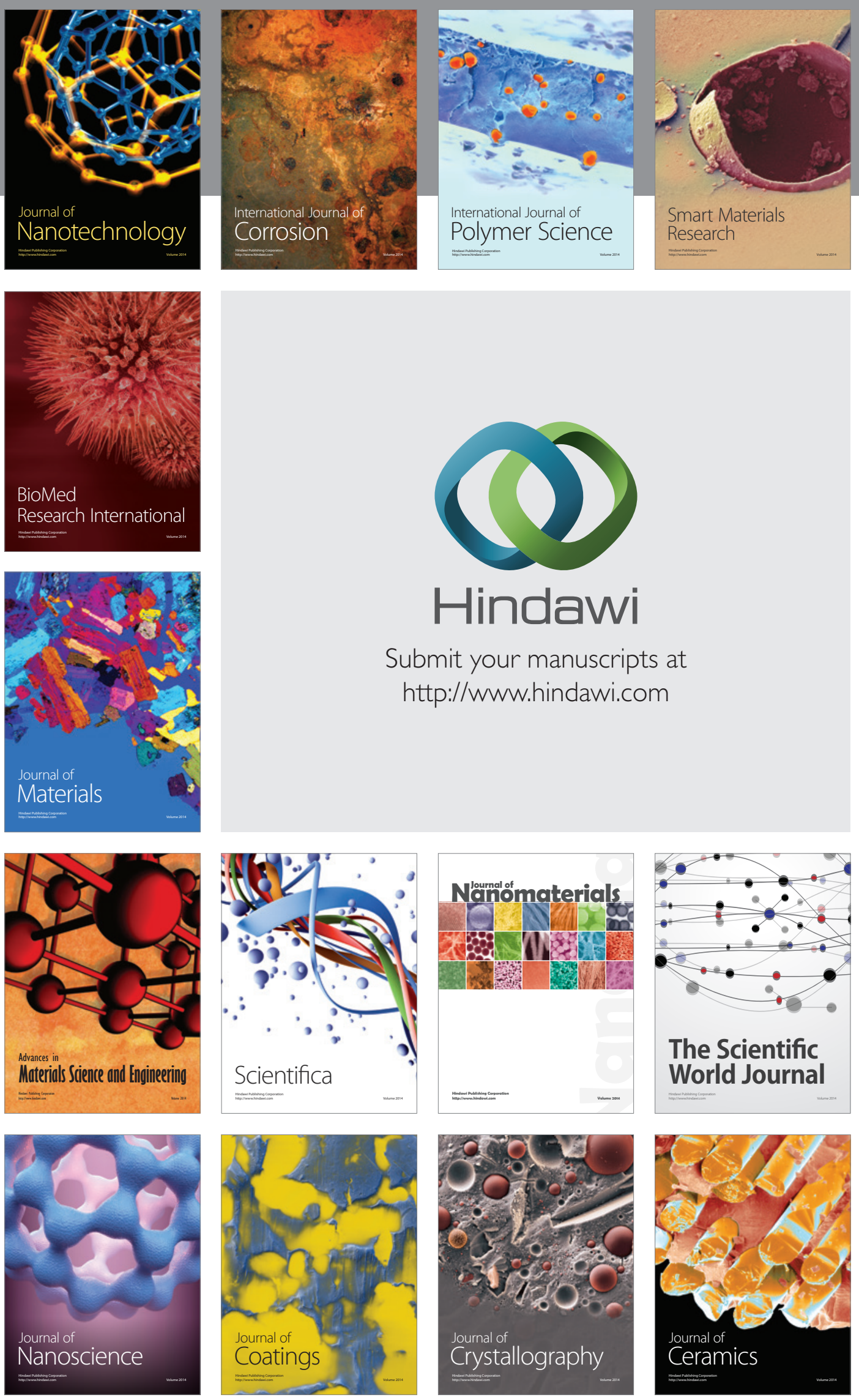

The Scientific World Journal

Submit your manuscripts at

http://www.hindawi.com

\section{World Journal}

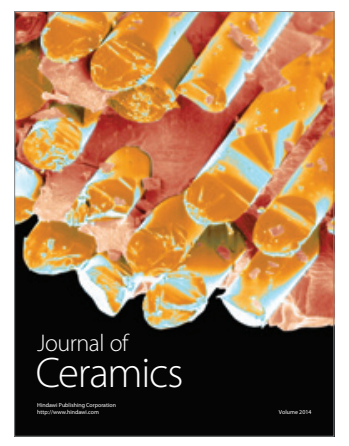

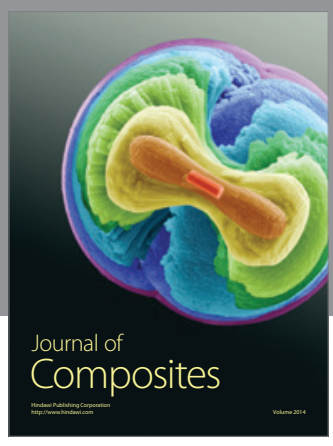
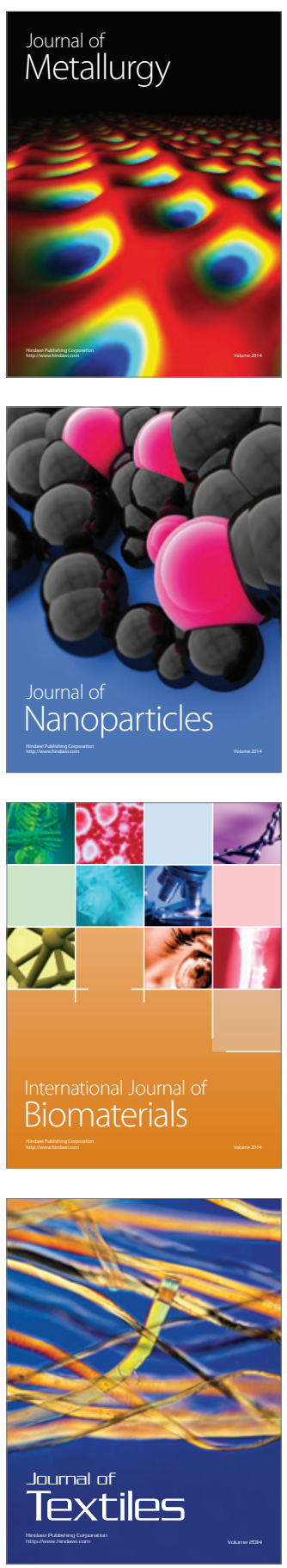